\title{
Genetic Control of the Mouse Cerebellum: Identification of Quantitative Trait Loci Modulating Size and Architecture
}

\author{
David C. Airey, Lu Lu, and Robert W. Williams \\ Center for Neuroscience and Department of Anatomy and Neurobiology, University of Tennessee, Memphis, \\ Tennessee 38163
}

To discover genes influencing cerebellum development, we conducted a complex trait analysis of variation in the size of the adult mouse cerebellum. We analyzed two sets of recombinant inbred BXD strains and an F2 intercross of the common inbred strains, C57BL/6J and DBA/2J. We measured cerebellar size as the weight or volume of fixed or histologically processed tissue. Among BXD recombinant inbred strains, the cerebellum averages $52 \mathrm{mg}$ (12.4\% of the brain) and ranges $18 \mathrm{mg}$ in size. In F2 mice, the cerebellum averages $62 \mathrm{mg}$ (12.9\% of the brain) and ranges $\sim 20 \mathrm{mg}$ in size. Five quantitative trait loci (QTLs) that significantly control variation in cerebellar size were mapped to chromosomes 1 (Cbs1a), 8 (Cbs8a), 14 (Cbs14a), and 19 (Cbs19a, Cbs19b). In combination, these QTLs can shift cere- bellar size an appreciable $35 \%$ of the observed range. To assess regional genetic control of the cerebellum, we also measured the volume of the cell-rich, internal granule layer (IGL) in a set of BXD strains. The IGL ranges from 34 to $43 \%$ of total cerebellar volume. The QTL Cbs8a is significantly linked to variation in IGL volume and is suggestively linked to variation in the number of cerebellar folia. The QTLs we have discovered are among the first loci shown to modulate the size and architecture of the adult mouse cerebellum.

Key words: neurogenetics; quantitative trait locus; QTL; cerebellum; internal granule cell layer; IGL; C57BL/6J; DBA/2J; $B X D$; recombinant inbred strain; F2 intercross; folia
The cerebellum displays striking quantitative and structural diversity, ranging from a simple, flat sheet in turtles and frogs to an enormous, hyperfolded configuration in mormyrid fish (Butler and Hodos, 1996; Voogd and Glickstein, 1998). Even among closely related primate species, the cerebellum displays important differences in size and form (Finlay and Darlington, 1995; Rilling and Insel, 1998; Barton and Harvey, 2000). The internal cellular composition of the cerebellum, however, is highly conserved: three laminae overlay internal white matter and deep cerebellar nuclei in most taxonomic groups. The contrast between highly variable size and shape yet tightly conserved programs of cell differentiation indicates that genetic modulation of the cerebellum is primarily quantitative in nature (Llinás and Walton, 1998).

The cerebellum is an ideal structure in which to study molecular and genetic networks controlling morphogenesis in the CNS. Its laminar cytoarchitecture and modular structure facilitate the study of developmental compartments (Herrup and Kuemerle, 1997), the effects of single-gene mutations (Goldowitz and Eisenman, 1992; Heintz and Zoghbi, 2000), and normal individual differences (Inouye and Oda, 1980; Neumann et al., 1990; Cooper et al., 1991; Wahlsten and Andison, 1991, 1993). The networks of genes that are critical in cerebellar development are beginning to be identified (Goldowitz and Hamre, 1998; Oberdick et al., 1998). For example, Yang et al. (1999) recently reported a convincing dependence on Ziprol gene dosage for granule cell number and folial patterning in

\footnotetext{
Received Oct. 30, 2000; revised March 16, 2001; accepted April 6, 2001.

This work was supported by a grant from the National Institute of Neurological Disorders and Stroke (R01 NS35485). We thank Drs. Glen Rosen, Emmanuel Gilissen, Guomin Zhou, Jing Gu, and Xiyun Peng for their assistance in generating, processing, or genotyping $\mathrm{BXD}$ and $\mathrm{F} 2$ mice.

Correspondence should be addressed to Dr. David C. Airey, Center for Neuroscience and Department of Anatomy and Neurobiology, University of Tennessee, 855 Monroe Avenue, Memphis, TN 38163. E-mail: dairey@nb.utmem.edu. Copyright (C) 2001 Society for Neuroscience $0270-6474 / 01 / 215099-11 \$ 15.00 / 0$
}

the mouse cerebellum. Relatively subtle quantitative effects on cerebellar size and foliation have also been well demonstrated for Engrailed-2 null mice (Joyner et al., 1991; Millen et al., 1994; Kuemerle et al., 1997). Null mutant, induced expression, or other transgenic technologies are indispensable for molecular dissection of cerebellar development. It remains unknown whether these (or other) early patterning genes are responsible for normal differences between inbred mice, wild mouse populations, or larger species differences. We might expect early patterning genes to be fixed within species and that later acting genes tolerate the polymorphisms that realize individual differences.

Recent advances in quantitative genetics allow neurogeneticists to systematically identify the polymorphic gene loci that, in concert with environmental influences, generate quantitative variation. This forward genetic approach, i.e., from trait to gene, initially involves associating differences in alleles near defined marker loci with differences in the relevant trait. A strong statistical association indicates the location and effect size of a quantitative trait locus (QTL) (Darvasi, 1998; Williams, 2000). In one of the first studies of gene loci affecting normal strain differences in the mouse CNS, Neumann et al. (1993) reported three loci that have quantitative effects on the number of cerebellar fissures in mice derived from the $\mathrm{C} 57 \mathrm{BL} / 6 \mathrm{~J}$ and $\mathrm{DBA} / 2 \mathrm{~J}$ inbred strains. Most recently, in the NZB/BINJ and C57BL/6By inbred strains, LeRoy-Duflos (2001) identified seven loci affecting the presence or absence of the declival and intraculminate cerebellar fissures. Furthermore, LeRoy-Duflos (2001) colocalized one of these gene loci with a measure of motor coordination, illustrating a potentially powerful approach to investigate possible causal relationships between CNS structure and function. By taking advantage of differences between normal strains of mice, we have recently mapped gene loci that modulate numbers of neurons in mouse retina (Strom and Williams, 1998; Williams et al., 1998), olfactory 
bulb weight (Williams et al., 2001), and hippocampus weight and internal architecture (Lu et al., 2001).

In the present study we have initiated a neurogenetic analysis of the normal adult mouse cerebellum. Using experimental crosses of mice derived from C57BL/6J and DBA/2J inbred strains, we have started our analysis by first considering genes that affect total cerebellar size and the size of the cell-rich internal granule layer. We demonstrate that differences in cerebellar anatomy are generated in part by a set of five QTLs with relatively large effects that map to chromosomes $1,8,14$, and 19 .

\section{MATERIALS AND METHODS}

Mice. Three complementary sets of mice were used in this study $(n=$ 514). These included two sets of BXD recombinant inbred (RI) strains and a set of F2 progeny. The RI strains and F2 progeny were generated from the inbred strains C57BL/6J ( $B$ for short) and DBA/2J ( $D$ for short). RI mice are inbred lines derived from brother-sister matings starting from an F2 intercross. In general, RI strains, when compared with F2 mice, provide lower power but increased mapping resolution for QTL detection. This is because RI sets are small (usually $<30$ strains) but harbor 3.5-4 times as many recombination events compared with F2 mice. Because they are inbred, RI lines also allow greater precision in phenotyping. The average of several mice can represent the mean value for a strain. The BXD RI strains were generated by Dr. B. A. Taylor (Taylor, 1989; Taylor et al., 1999), and purchased from The Jackson Laboratory (Bar Harbor, ME) from 1994 through $1999(n=334)$. The parental strains used to generate F2 mice were purchased from The Jackson Laboratory. The F2 animals were generated at the University of Tennessee (UT) by intercrossing both BDF1 and DBF1 mice as described in Zhou and Williams (1999). One hundred and five of these F2 mice were BDF2s and 75 were DBF2s. Mice were maintained at $20-24^{\circ} \mathrm{C}$ on a 14:10 on:off photoperiod in a pathogen-free colony at UT. Most animals were provided with tap water and a 5\% fat Agway Prolab 3000 rat and mouse chow ad libitum. The average age of the BXD RI strains was $\sim 80 \mathrm{~d}$ (range, $\sim 30-300$ ), and that of the F2 mice was $100 \mathrm{~d}$ (range, $\sim 70-160$ ). Both females and males were studied.

Cerebellum. Mice were deeply anesthetized with Avertin (1.25\% 2,2,2tribromoethanol and $0.8 \%$ tert-pentyl alcohol in water; $0.8-1.0 \mathrm{ml}$, i.p.) and weighed to the nearest $0.1 \mathrm{gm}$. Most mice were perfused transcardially with $0.1 \mathrm{M}$ PBS followed first by $1.25 \%$ glutaraldehyde and $1.0 \%$ paraformaldehyde in $0.1 \mathrm{M}$ PBS and then by $2.5 \%$ glutaraldehyde and $2.0 \%$ paraformaldehyde in $0.1 \mathrm{M}$ PBS.

Brains from BXD and F2 mice were dissected from the skull, sectioned free of the spinal cord and cranial nerves, rolled briefly on tissue paper, and weighed to the nearest $0.1 \mathrm{mg}$. All weights were recorded at room temperature. The cerebellum was dissected free of each brain by inserting a small knife parallel to the dorsal hindbrain surface to cut the peduncles. Two persons dissected cerebellar weights from BXD mice. Technical error was controlled before QTL mapping by using a covariate term (coded as a dummy or indicator variable) (Table 1, note b).

In a second set of BXD mice, brain, cerebellum, and internal granule layer (IGL) volumes were measured from celloidin-embedded Nissl-stained sections available from the Mouse Brain Library. Brain and cerebellum volumes were estimated by summing the areas measured across sections and multiplying the sum by the sampling interval $(0.30 \mathrm{~mm})$. This method does not differ significantly from Cavalieri's method for the number of sections per mouse $(>10)$ measured (Rosen and Harry, 1990). Measurements were made on slide images using NIH Image software (developed at the United States National Institutes of Health). The volume of the internal granule layer was measured using the density slice feature of NIH Image (Fig. 1). As measured, this volume included the internal granule layer (predominantly the somas of the granule cells) and the adjoining Purkinje cell layer (somas). Cerebellum and IGL volumes were corrected for differences in tissue shrinkage by dividing by the total brain volume and multiplying by the brain volume expected from the known brain weight, assuming a uniform brain density of one milligram per cubic millimeter of fixed tissue.

Genotyping. Genomic DNA from F2 mice was extracted from the spleen using a high salt procedure (Laird et al., 1991). Spleens were removed under anesthesia just before perfusion. A set of 145 microsatellite loci distributed across all autosomes, and the $\mathrm{X}$ chromosome was typed in the F2 progeny using a modified protocol of Love et al. (1990) and Dietrich et al. (1992). Each $10 \mu \mathrm{l}$ PCR reaction contained $1 \times$ PCR buffer, $1.92 \mathrm{~mm} \mathrm{MgCl}_{2}, 0.25 \mathrm{U}$ of Taq DNA polymerase, $0.2 \mathrm{~mm}$ of each deoxynucleotide, $132 \mathrm{nM}$ of the primers, and $50 \mathrm{ng}$ of genomic DNA. The microsatellite primers were purchased from Research Genetics (Huntsville, AL). A loading dye ( $60 \%$ sucrose, $1.0 \mathrm{~mm}$ cresol red) was added to the reaction before the PCR (Dietrich et al., 1994). PCRs were performed in 96 well microtiter plates. A high-stringency touchdown protocol was used to lower the annealing temperature progressively from 60 to $50^{\circ} \mathrm{C}$ in $2^{\circ} \mathrm{C}$ steps over the first six cycles (Don et al., 1991). After 30 cycles, PCR products were run on 2.5\% Metaphor agarose gels (FMC Bioproducts, Rockland, ME), stained with ethidium bromide, and photographed. Genotypes were scored, entered into Microsoft Excel 98, formatted, and exported to Map Manager QT and Map Manager QTX (Manly and Olson, 1999). A nonredundant set of $~ 320$ loci typed for all 35 BXD RI strains was used for analysis, as described in Williams et al. (1998) and Zhou and Williams (1999).

Statistics. Regression analysis was performed to explore and remove (i.e., statistically control) covariance between cerebellum or IGL size and other variables before QTL mapping. The primary purpose of this analysis was to provide protection against claiming that a gene effect is specific to cerebellum or IGL size when the effect is more general, e.g., a whole brain or body effect. Our variables included cerebellum weight (in milligrams) or volume (in cubic millimeters), IGL volume (in cubic millimeters), brain weight (in milligrams) or volume (in cubic millimeters), body weight (grams), sex, and age (days). The regression analysis resulted in a set of new brain phenotypes based on the residuals from linear regression models; these "adjusted" phenotypes were used for gene mapping. A secondary purpose of the regression analysis was to understand relations between brain phenotypes and factors like sex or age. Regression models were computed with Data Desk 6.1. Interaction terms were explored in each model and excluded from final models when not significant. Alternatives to this regression analysis include multiple trait QTL analysis (Jiang and Zeng, 1995) or the use of covariates during single trait QTL analysis (Map Manager QT manual). We chose single trait QTL analysis because we were specifically interested in cerebellum QTLs. We chose to control variance related to factors like brain size, sex, and age before QTL mapping, because these factors are of independent biological interest and potentially confounding.

Map Manager QT and QTX programs (Manly and Olson, 1999) were used for QTL mapping. In essence, QTL mapping divides a panel of mice into groups based on their genotypes (e.g., $B B$ or $D D$ in the case of RI strains and $B B, B D$, and $D D$ in the case of F2 progeny) at defined chromosomal loci and compares these groups using a quantitative phenotype (e.g., cerebellum weight). QTL mapping generally proceeds from analysis at defined loci (single marker analysis), to positions inferred between loci (simple interval mapping), and then to positions inferred between loci but with statistical control for other loci known to affect the trait (composite interval mapping). Interval mapping helps to better localize QTLs between markers. Composite interval mapping helps to understand the independent or incremental effects of QTLs. By controlling for multiple unlinked QTLs, the power to detect secondary QTLs may also be increased substantially. In our genome scans we first mapped our phenotype against genotype data on a locus-by-locus basis to assess linkage. Loci with log of the odds ratio (LOD) scores greater than $\sim 2.8$ were considered suggestive (Lander and Kruglyak, 1995). Chromosomes harboring suggestive loci were analyzed by simple interval mapping. When more than one locus was identified, composite interval mapping was used. Map Manager QT and QTX implement simple and composite interval mapping using methods described by Haley and Knott (1992). Genome-wide (experimentwise) significance probabilities for mapped QTLs were estimated by comparing peak likelihood ratio statistics $($ LRSs $)($ LRS $=$ LOD $\times 4.6$; Liu, 1998) of correctly ordered data sets with those computed for 10,000 permutations of the phenotype data (Churchill and Doerge, 1994). Probabilities reported below as "genomewide" $\left(P_{\mathrm{G}}\right)$ reflect correction for multiple tests; other reported probabilities are comparisonwise. Confidence of QTL position is given as the 2-LOD support interval that bounds the QTL with $\sim 95 \%$ confidence (Lynch and Walsh, 1998).

\section{RESULTS}

Our results are divided into two parts. The first section describes the normative phenotypic measures and their relation to differences in sex, age, body weight, and brain weight. The second section presents evidence for QTLs modulating cerebellar size and structure. 
Table 1. Cerebellum weight and volume in BXD recombinant inbred strains

\begin{tabular}{|c|c|c|c|c|c|c|c|c|c|}
\hline Strain & $n$ & $\begin{array}{l}\text { Cerebellum } \\
\text { weight }^{a}\end{array}$ & $\begin{array}{l}\text { Adjusted } \\
\text { cerebellum }^{b} \\
\text { weight }^{b}\end{array}$ & $\begin{array}{l}\text { Brain } \\
\text { weight }^{c}\end{array}$ & $n^{d}$ & $\begin{array}{l}\text { Cerebellum } \\
\text { volume }^{e}\end{array}$ & $\begin{array}{l}\text { Adjusted } \\
\text { cerebellum } \\
\text { volume }^{f}\end{array}$ & IGL volume $^{g}$ & $\begin{array}{l}\text { Adjusted } \\
\text { IGL volume }^{h}\end{array}$ \\
\hline 1 & 5 & $61.4 \pm 2.38$ & $54.1 \pm 0.95$ & $483 \pm 20.3$ & 5 & $49.8 \pm 2.32$ & $46.0 \pm 1.89$ & $20.3 \pm 1.81$ & $18.7 \pm 1.60$ \\
\hline 2 & 5 & $49.0 \pm 1.25$ & $50.1 \pm 0.71$ & $403 \pm 8.6$ & 6 & $45.5 \pm 1.23$ & $44.9 \pm 1.42$ & $15.0 \pm 0.93$ & $14.8 \pm 0.91$ \\
\hline 5 & 5 & $62.5 \pm 2.32$ & $53.3 \pm 1.01$ & $501 \pm 13.0$ & 4 & $62.9 \pm 3.55$ & $52.5 \pm 3.41$ & $23.0 \pm 0.20$ & $18.7 \pm 0.50$ \\
\hline 6 & 7 & $53.1 \pm 1.22$ & $55.1 \pm 0.71$ & $403 \pm 5.0$ & - & - & - & - & - \\
\hline 8 & 7 & $59.1 \pm 2.07$ & $57.3 \pm 0.32$ & $438 \pm 22.9$ & 8 & $55.1 \pm 1.64$ & $54.3 \pm 1.87$ & $22.7 \pm 1.00$ & $22.4 \pm 1.16$ \\
\hline 9 & 7 & $53.9 \pm 1.05$ & $51.2 \pm 0.99$ & $448 \pm 9.6$ & 5 & $47.3 \pm 1.10$ & $45.8 \pm 1.02$ & $18.8 \pm 0.55$ & $18.1 \pm 0.55$ \\
\hline 11 & 5 & $53.1 \pm 1.10$ & $53.6 \pm 0.79$ & $408 \pm 5.8$ & 5 & $50.6 \pm 1.21$ & $49.0 \pm 1.01$ & $19.5 \pm 0.82$ & $18.9 \pm 0.78$ \\
\hline 12 & 5 & $45.9 \pm 1.09$ & $46.8 \pm 0.83$ & $405 \pm 16.9$ & 6 & $43.8 \pm 1.75$ & $42.6 \pm 1.30$ & $16.4 \pm 1.04$ & $16.0 \pm 0.86$ \\
\hline 13 & 5 & $48.4 \pm 1.63$ & $50.6 \pm 0.65$ & $392 \pm 12.9$ & 5 & $47.9 \pm 1.18$ & $48.3 \pm 1.09$ & $18.6 \pm 1.78$ & $18.8 \pm 1.64$ \\
\hline 14 & 5 & $49.4 \pm 0.44$ & $49.3 \pm 0.44$ & $414 \pm 6.6$ & 5 & $47.1 \pm 1.71$ & $45.0 \pm 1.64$ & $15.8 \pm 0.69$ & $14.9 \pm 0.91$ \\
\hline 15 & 7 & $47.4 \pm 1.15$ & $45.7 \pm 0.38$ & $437 \pm 14.2$ & 5 & $44.5 \pm 0.87$ & $41.6 \pm 0.80$ & $15.2 \pm 0.53$ & $14.0 \pm 0.54$ \\
\hline 16 & 5 & $56.3 \pm 1.21$ & $52.5 \pm 0.68$ & $450 \pm 6.8$ & - & - & - & - & - \\
\hline 18 & 5 & $53.6 \pm 1.44$ & $52.0 \pm 0.68$ & $429 \pm 11.9$ & 5 & $47.5 \pm 2.23$ & $47.8 \pm 2.06$ & $18.6 \pm 1.27$ & $18.8 \pm 1.11$ \\
\hline 19 & 6 & $50.1 \pm 1.42$ & $51.1 \pm 0.62$ & $409 \pm 15.9$ & 5 & $46.4 \pm 1.16$ & $45.8 \pm 0.64$ & $18.5 \pm 1.19$ & $18.3 \pm 1.30$ \\
\hline 20 & 5 & $48.2 \pm 1.67$ & $52.4 \pm 0.75$ & $374 \pm 13.3$ & 5 & $43.2 \pm 0.96$ & $45.8 \pm 0.83$ & $14.5 \pm 0.57$ & $15.9 \pm 0.53$ \\
\hline 21 & 7 & $50.6 \pm 1.31$ & $49.0 \pm 0.77$ & $437 \pm 8.7$ & - & - & - & - & - \\
\hline 22 & 5 & $53.8 \pm 1.51$ & $51.6 \pm 0.64$ & $435 \pm 12.3$ & 5 & $50.4 \pm 1.47$ & $48.0 \pm 1.03$ & $21.6 \pm 1.56$ & $20.6 \pm 1.50$ \\
\hline 23 & 5 & $48.6 \pm 1.03$ & $50.7 \pm 0.34$ & $394 \pm 8.1$ & 5 & $43.1 \pm 1.21$ & $43.9 \pm 1.61$ & $16.4 \pm 0.77$ & $16.8 \pm 0.76$ \\
\hline 24 & 5 & $54.9 \pm 1.92$ & $55.5 \pm 1.18$ & $408 \pm 9.6$ & 5 & $50.7 \pm 3.52$ & $52.2 \pm 3.52$ & $21.1 \pm 1.73$ & $21.8 \pm 1.71$ \\
\hline 25 & 5 & $49.6 \pm 0.81$ & $52.6 \pm 0.33$ & $385 \pm 4.9$ & 5 & $45.1 \pm 1.05$ & $46.6 \pm 0.75$ & $17.3 \pm 1.13$ & $17.9 \pm 1.01$ \\
\hline 27 & 5 & $47.4 \pm 2.25$ & $53.1 \pm 0.61$ & $359 \pm 16.2$ & 5 & $43.5 \pm 2.00$ & $49.3 \pm 1.44$ & $16.9 \pm 1.15$ & $19.3 \pm 1.11$ \\
\hline 28 & 5 & $51.5 \pm 0.87$ & $53.5 \pm 0.58$ & $394 \pm 4.3$ & 5 & $47.7 \pm 1.90$ & $49.3 \pm 1.93$ & $18.9 \pm 0.98$ & $19.5 \pm 0.88$ \\
\hline 29 & 5 & $50.2 \pm 0.56$ & $53.2 \pm 0.30$ & $385 \pm 4.5$ & 5 & $40.9 \pm 2.35$ & $46.0 \pm 1.31$ & $14.9 \pm 1.10$ & $17.0 \pm 0.82$ \\
\hline 30 & 5 & $53.6 \pm 1.14$ & $58.7 \pm 0.79$ & $365 \pm 6.2$ & 5 & $47.9 \pm 2.11$ & $52.6 \pm 1.47$ & $17.8 \pm 1.01$ & $19.8 \pm 0.84$ \\
\hline 31 & 5 & $49.7 \pm 0.91$ & $50.8 \pm 0.58$ & $403 \pm 8.5$ & 5 & $46.0 \pm 1.81$ & $46.8 \pm 2.04$ & $16.5 \pm 1.37$ & $16.9 \pm 1.49$ \\
\hline 32 & 5 & $56.0 \pm 1.19$ & $53.3 \pm 0.98$ & $439 \pm 6.0$ & 4 & $55.1 \pm 3.66$ & $51.5 \pm 3.28$ & $21.2 \pm 0.65$ & $19.7 \pm 0.64$ \\
\hline 33 & 5 & $52.1 \pm 0.66$ & $51.9 \pm 0.57$ & $445 \pm 3.0$ & 4 & $48.2 \pm 3.13$ & $47.7 \pm 3.61$ & $19.5 \pm 1.24$ & $19.3 \pm 1.50$ \\
\hline 34 & 5 & $53.7 \pm 1.22$ & $54.1 \pm 0.68$ & $439 \pm 5.2$ & 5 & $50.4 \pm 2.85$ & $51.0 \pm 2.10$ & $18.7 \pm 1.57$ & $18.9 \pm 1.27$ \\
\hline 35 & 4 & $49.7 \pm 2.03$ & $52.3 \pm 0.75$ & $417 \pm 14.4$ & 5 & $46.9 \pm 1.96$ & $48.2 \pm 1.19$ & $17.6 \pm 1.17$ & $18.2 \pm 0.92$ \\
\hline 36 & 5 & $44.5 \pm 0.73$ & $46.1 \pm 0.30$ & $427 \pm 6.3$ & 5 & $40.9 \pm 1.29$ & $42.5 \pm 0.87$ & $14.6 \pm 0.56$ & $15.3 \pm 0.61$ \\
\hline 38 & 4 & $51.1 \pm 1.79$ & $51.8 \pm 0.78$ & $436 \pm 9.6$ & 5 & $45.5 \pm 2.46$ & $45.8 \pm 2.00$ & $16.8 \pm 1.01$ & $16.9 \pm 0.78$ \\
\hline 39 & 5 & $54.9 \pm 0.87$ & $57.0 \pm 0.46$ & $423 \pm 5.3$ & 4 & $50.6 \pm 1.64$ & $52.6 \pm 0.41$ & $18.9 \pm 1.42$ & $19.8 \pm 0.94$ \\
\hline 40 & 4 & $49.9 \pm 1.13$ & $48.6 \pm 0.43$ & $455 \pm 8.2$ & 5 & $44.9 \pm 3.90$ & $44.2 \pm 3.87$ & $18.1 \pm 0.86$ & $17.8 \pm 0.97$ \\
\hline 42 & 5 & $59.4 \pm 0.95$ & $56.6 \pm 0.25$ & $469 \pm 7.0$ & 5 & $53.4 \pm 1.37$ & $51.1 \pm 1.01$ & $21.7 \pm 0.94$ & $20.8 \pm 0.82$ \\
\hline $\operatorname{Mean}^{i}$ & & 52.1 & 52.2 & 420 & & 47.8 & 47.7 & 18.2 & 18.2 \\
\hline $\mathrm{SD}^{i}$ & & 4.24 & 3.01 & 31.9 & & 4.56 & 3.33 & 2.37 & 1.02 \\
\hline
\end{tabular}

BXD strain means for cerebellar phenotypes. Columns containing "adjusted" values reflect weights or volumes after covariance with brain size has been removed.

- , Not available or not measured.

${ }^{a}$ Mean \pm SE (in milligrams) for unadjusted observations.

${ }^{b}$ Means for $\mathrm{Cb}$ Weight $_{\mathrm{i}}-\left[5.66+0.11\left(\right.\right.$ brain weight $\left._{\mathrm{i}}\right)+3.06\left(\right.$ dissector identity $\left.\left._{\mathrm{i}}\right)\right]+\mathrm{Cb}$ weight grand mean; see Materials and Methods.

${ }^{c}$ Unadjusted observations. These values also represent expected brain volumes in cubic millimeters; see Materials and Methods.

${ }^{d}$ Independent sets of mice were used for weight and volume estimates.

${ }^{e}$ Mean \pm SE (cubic millimeters). Adjusted for tissue shrinkage (Cb volume/brain volume $\times$ expected brain volume; see Materials and Methods).

${ }^{f} \mathrm{Cb}_{\text {Volume }}-\left[9.23+0.09\left(\right.\right.$ expected brain volume $\left.\left.{ }_{\mathrm{i}}\right)\right]+\mathrm{Cb}$ volume grand mean.

${ }^{g}$ Adjusted for tissue shrinkage (IGL volume/brain volume $\times$ expected brain volume; see Materials and Methods).

${ }^{h}$ IGL Volume $_{\mathrm{i}}-\left[2.00+0.04\left(\right.\right.$ expected brain volume $\left.\left._{\mathrm{i}}\right)\right]+$ IGL volume grand mean.

${ }^{i}$ Calculated from strain estimates, not from individual observations.

\section{Cerebellar size and variation}

\section{Parental cerebella}

The cerebella of C57BL/6J mice are on average $18 \%$ larger $\left(F_{(1,58)}=110 ; p<0.0001\right)$ than those of DBA/2J mice: $59.6 \pm$ $0.52 \mathrm{mg}(n=36 ; 15$ male, 21 female $)$ versus $50.5 \pm 0.73 \mathrm{mg}(n=$ 24; 11 male, 13 female). Male and female mice do not differ in cerebellar weight within these strains. Despite the significant $18 \%$ difference in absolute size, the cerebellum makes up $\sim 12 \%$ of total brain weight in both strains. This contrast highlights the importance of assessing specificity of gene effects or the need to determine whether loci affect cerebellar size directly or indirectly (e.g., through brain or body size).

\section{BXD cerebella}

The random assortment of multiple alleles at different loci will often generate much greater differences among RI strains than between the parental strains (Neumann et al., 1993; Lu et al., 2001; Williams et al., 2001). This is definitely the case for the 

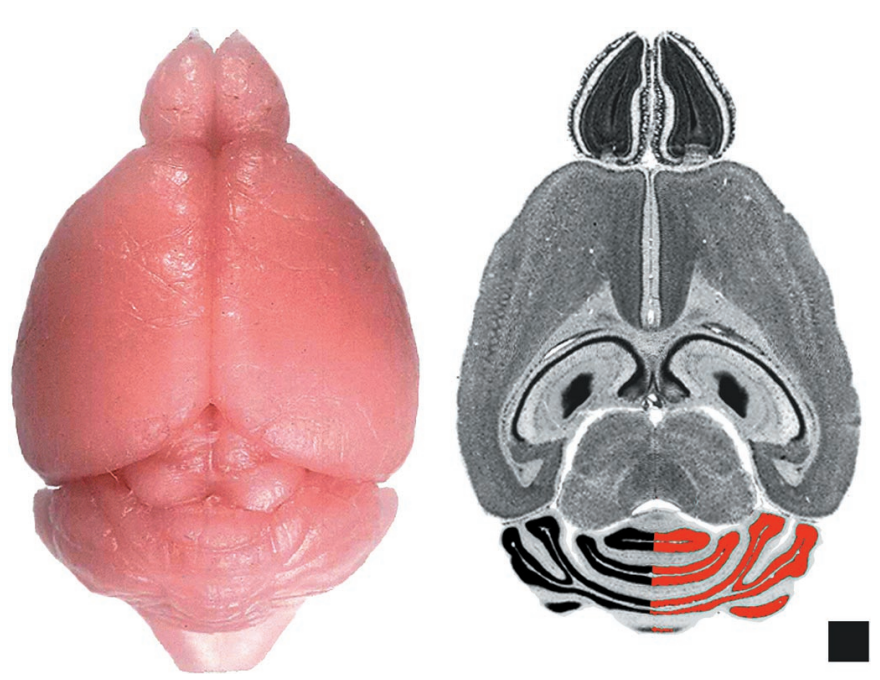

Figure 1. Dissecting the cerebellum. Left, Dorsal view of a fixed mouse brain. Right, Horizontal section from the Mouse Brain Library illustrating the method used to measure IGL volume. Half of the IGL is measured here for illustrative purposes only. Scale bar, $1 \mathrm{~mm}$.

cerebella of BXD strains. Weights range from a low of $45.9 \pm$ $1.09 \mathrm{mg}$ in BXD12 to a high of $62.5 \pm 2.32 \mathrm{mg}$ in BXD5 (Table 1). In a separate sample of BXD mice, cerebellar volumes range from $43.1 \pm 1.21 \mathrm{~mm}^{3}$ in BXD23 to $62.9 \pm 3.55 \mathrm{~mm}^{3}$ in BXD5. Strain distribution patterns for either measure of cerebellar size do not depart significantly from normality (Kolmogorov tests), arguing that the strain differences are polygenic in origin (cf. Williams et al., 1998). The correlation between strain means for cerebellar weight and volume is high and significant $(r=0.86 ; p<$ 0.0001). Using ANOVA with strain as the single factor, strain differences are significant for cerebellar weight $\left(R^{2}=67.5 \%\right.$; $\left.F_{(33,144)}=9.1 ; p<0.0001\right)$ and volume $\left(R^{2}=51.9 \%, F_{(30,124)}=\right.$ $4.5 ; p<0.0001)$. Using estimates of environmental and genetic influences on cerebellum size from within strain and between strain variances $\left[0.5 V_{\mathrm{A}} /\left(0.5 V_{\mathrm{A}}+V_{\mathrm{E}}\right)\right]$, the heritability is $\sim 47 \%$ and $33 \%$ for weight and volume, respectively (Hegmann and Possidente, 1981).

\section{F2 cerebella}

The average cerebellar weight of $180 \mathrm{~F} 2$ mice is $61.5 \pm 0.33 \mathrm{mg}$. The distribution of cerebellar weight in F2 mice is bell-shaped and is not significantly different from a normal distribution (Kolmogorov test) (Fig. 2). Cerebellar weight in the F1 mice averages $62.1 \pm 0.63 \mathrm{mg}(n=46)$. In a single-factor ANOVA with F1, F2, and parental mice, the parental strains differ from each other (Scheffe post hoc test; $p<0.0001)$, F1 mice differ from D mice $(p<0.0001)$ but not $\mathrm{B}$ mice $(p=0.10)$, and $\mathrm{F} 1$ and $\mathrm{F} 2$ mice do not differ significantly $(p=0.80)$. Using variances in the isogenic $\mathrm{F} 1$ and heterogeneous $\mathrm{F} 2$ samples, $\left(V_{\mathrm{F} 2}-V_{\mathrm{F} 1}\right) / V_{\mathrm{F} 2}$, heritability of cerebellum weight is $23 \%$.

\section{$B X D$ and $F 2$ differences}

There are significant differences between the $\mathrm{F} 2$ and BXD mice: cerebellar weight is on average $10 \mathrm{mg}$ heavier, brain weight is 45 $\mathrm{mg}$ heavier, and body weight is $6.7 \mathrm{gm}$ heavier in F2 mice. The age and sex composition of our samples are also somewhat different. The F2 mice are on average $10 \mathrm{~d}$ older, but the age range is comparatively narrow (66-156 d vs $30-300 \mathrm{~d}$ ). The F2 sample is $52 \%$ female, whereas the BXD sample is $44 \%$ female. The cerebellar weight of F2 cases are still significantly higher (4 mg)

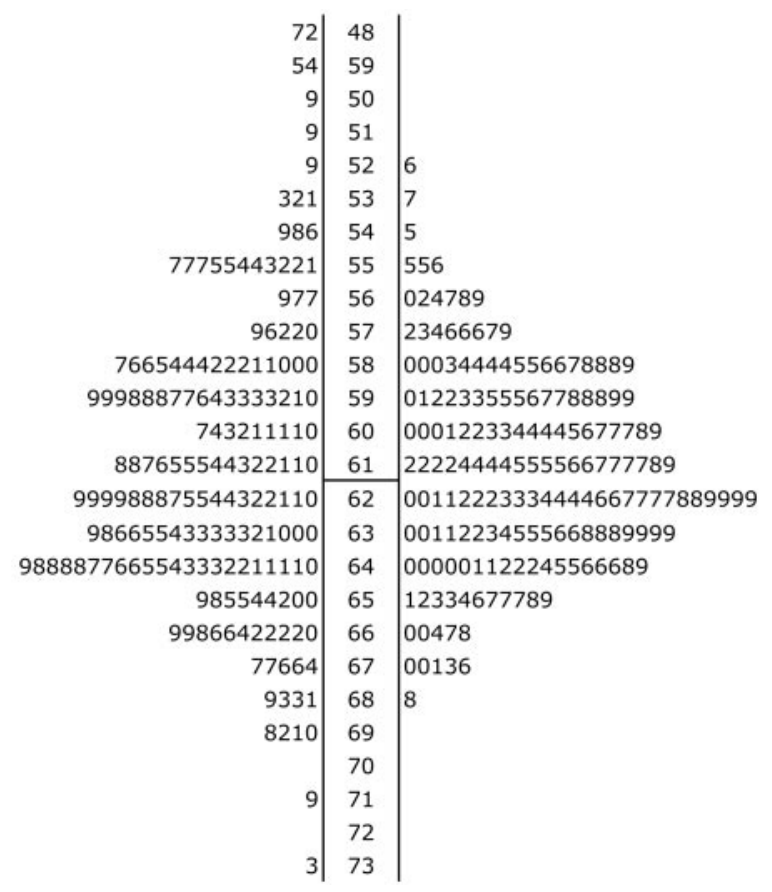

Figure 2. Distribution of cerebellar weights in the F2 intercross as illustrated by stem-and-leaf plots. The values on the left are the observed values, and those on the right reflect correction by regression for brain weight. The mean for both distributions is marked by a horizontal line. From this graph, the distributions are illustrated, and the original data are presented. For example, the right distribution shows an overall normal curve, and that there are three cases with the adjusted cerebellar weights between 55 and $56 \mathrm{mg}(55.5,55.5$, and $55.6 \mathrm{mg})$.

after adding covariates for brain weight, body weight, sex, and age $\left(F_{(1,344)}=53 ; p<0.0001\right)$. The increased size of $\mathrm{F} 2$ mice likely reflects heterosis of the non-inbred F2 progeny and F1 maternal superiority (Lynch and Walsh, 1998).

\section{Cerebellar covariate analysis}

Sex is not associated with differences in cerebellar size. When restricted to $19 \mathrm{BXD}$ strains for which both sexes were replicated, no sex difference is evident $\left(F_{(1,100)}=0.21 ; p=0.65\right)$. Sex is also not an important predictor in either BXD cerebellar volume $\left(F_{(1,88)}=0.14 ; p=0.71 ; 18\right.$ strains $)$ or $\mathrm{F} 2$ cerebellar weight $\left(F_{(1,178)}=0.03 ; p=0.86\right)$.

Increased body weight is weakly associated with larger cerebella. In BXD mice, body weight has a correlation of 0.36 with cerebellar weight $(\mathrm{df}=162 ; p<0.0001)$ and 0.34 with cerebellar volume ( $\mathrm{df}=148 ; p<0.0001)$. In the $\mathrm{F} 2$ data set, the correlation is $0.19(\mathrm{df}=177 ; p=0.014)$.

Age is also weakly associated with cerebellar size. In BXD mice, cerebellar weight correlates 0.27 with age $(\mathrm{df}=174 ; p=$ $0.0003 ; 30-300 \mathrm{~d}$; log-transformed), and cerebellar volume correlates 0.19 with age $(\mathrm{df}=150 ; p=0.01)$. We did not detect any increase in cerebellar weight within the more restricted age sample of the F2 mice.

Brain size is strongly associated with cerebellar size. Cerebellar weight among BXD strains has a correlation of 0.70 with brain weight ( $\mathrm{df}=176 ; p<0.0001)$; for volume the correlation is 0.53 $(\mathrm{df}=153 ; p<0.0001)$. Cerebellar weight in $\mathrm{F} 2$ mice has a correlation of 0.72 with brain weight $(\mathrm{df}=178 ; p<0.0001)$. 


\section{Adjusted cerebellar size}

In multiple regression models including sex, body, age, and brain, only brain size is an important predictor of cerebellum for both BXD and F2 mice. Interactions are not significant. For these reasons, simple additive models including only brain weight or volume were used to create a set of adjusted measures for QTL mapping (Table 1 for adjusted BXD measures; Fig. 2 for adjusted F2 measures). Strain differences are still highly significant even after correction for differences in brain weight $\left(R^{2}=80.3 \%\right.$; $\left.F_{(33,144)}=17.78 ; p<0.0001\right)$ or brain volume $\left(R^{2}=45 \%\right.$; $\left.F_{(33,124)}=3.43 ; p<0.0001\right)$.

\section{Internal granule layer volume}

The volume of the internal granule layer ranges from a low of $14.5 \pm 0.57 \mathrm{~mm}^{3}$ in BXD20 to a high of $23.0 \pm 0.20 \mathrm{~mm}^{3}$ in BXD5 (Table 1). As a percentage of cerebellar volume, the IGL ranges from $33.6 \pm 2.2 \%$ (BXD14) to $42.9 \pm 2.9 \%$ (BXD22). Strain differences are again highly significant $\left(R^{2}=52 \% ; F_{(30,124)}\right.$ $=4.42 ; p<0.0001)$. Heritability for IGL volume is $\sim 31 \%$. The correlation between strain means (an estimate of the genetic correlation) for IGL volume and the remaining cerebellum volume (molecular layer, internal white matter, and deep nuclei) is $0.62(\mathrm{df}=29 ; p=0.0002)$. This correlation remains significant after variance associated with brain volume is removed $(r=0.41$; $\mathrm{df}=29 ; p=0.02)$.

\section{IGL covariate analysis}

Sex is not associated with differences in IGL volume. When restricted to $18 \mathrm{BXD}$ strains for which both sexes are replicated, no sex difference is evident $\left(F_{(1,88)}=0.27 ; p=0.61\right)$. Males and females are also not different in the volume of the rest of the cerebellum $\left(F_{(1,88)}=0.01 ; p=0.91\right)$.

Body weight is weakly associated with IGL volume $(r=0.17$; $\mathrm{df}=148 ; p=0.03)$, but more strongly associated with the rest of the cerebellum $(r=0.36$; df $=148 ; p<0.0001)$.

As with body weight, there is a dissociation between the effects of age on IGL volume and the volume of the rest of the cerebellum. Age (log-transformed) does not correlate with IGL volume $(r=0.05 ;$ df $=150 ; p=0.50)$ but does correlate with the remaining cerebellar volume $(r=0.23$; $\mathrm{df}=150 ; p=0.004)$.

Larger brains are positively associated with both greater IGL volume and the volume of the rest of the cerebellum. Brain volume is moderately correlated with IGL volume $(r=0.40$; $\mathrm{df}=$ $153 ; p<0.0001)$ and with the rest of the cerebellum $(r=0.46$; df $=153 ; p<0.0001)$.

\section{Adjusted IGL volume}

As was true for cerebellum size, analysis by multiple regression shows that only brain size significantly predicts IGL volume when sex, body, and age covariates are included. Interactions are not important predictors. A simple additive model including only brain volume was again used to create a set of adjusted IGL measures (Table 1). In contrast, the volume of the remainder of the cerebellum is predicted better by two factors: brain volume $\left(t_{1,147}=4.69 ; p<0.0001\right)$ and body weight $\left(t_{1,147}=2.50 ; p=0.01\right)$. Strain differences are significant for adjusted IGL volume $\left(R^{2}=\right.$ $\left.48 \% ; F_{(30,124)}=3.8 ; p<0.0001\right)$ and marginal for the adjusted cerebellar white matter $\left(R^{2}=28 \% ; F_{(30,119)}=1.6 ; p=0.05\right)$.

\section{QTL mapping}

\section{QTLs affecting cerebellar weight in BXD mice}

Single marker analysis shows that variation in adjusted cerebellar weight is associated with the pattern of $B$ and $D$ alleles at several
Table 2. Significant comparisonwise linkages for adjusted cerebellar weight in BXD mice

\begin{tabular}{lcrlll} 
Locus & Chr:cM & LRS & $\begin{array}{l}\text { Percent } \\
\text { variance } \\
\text { explained }\end{array}$ & Probability & $\begin{array}{l}\text { Additive } \\
\text { effect per } \\
\text { B allele }\end{array}$ \\
\hline D1Mit213 & $1: 26$ & 9.2 & 21 & 0.002 & -1.45 \\
D1Mit113 & $1: 92$ & 8.9 & 21 & 0.003 & -1.45 \\
D1Mit150 & $1: 100$ & 9.5 & 22 & 0.002 & -1.48 \\
D1Mit426 & $1: 101$ & 11.1 & 26 & 0.0008 & -1.58 \\
D8Mit147 & $8: 43$ & 16.3 & 36 & $5.5 \mathrm{e}-5$ & -1.84 \\
D8Mit312 & $8: 45$ & 19.7 & 42 & $9.3 \mathrm{e}-6$ & -1.98 \\
D8Mit211 & $8: 49$ & 19.2 & 41 & $1.2 \mathrm{e}-5$ & -2.08 \\
D8Mit113 & $8: 53$ & 14.3 & 32 & 0.0002 & -1.82 \\
D16Mit152 & $16: 57$ & 7.3 & 17 & 0.007 & +1.34 \\
D19Mit40 & $19: 25$ & 7.8 & 19 & 0.005 & -1.32 \\
\hline
\end{tabular}

The criteria for significance was set to $\alpha=0.01$.

microsatellite markers (Table 2), but linkages to mid-distal chromosome (Chr) 8 and distal Chr 1 appear strongest. Simple interval mapping of Chr 8 shows the tightest linkage ( $\mathrm{LRS}=22.5)$ to be just distal of D8Mit312 at $45 \mathrm{cM}$. At this locus, interval mapping estimates $47 \%$ of the variance in cerebellar weight is explained, and each $B$ allele is associated with a decrease of 2.5 $\mathrm{mg}$ (Fig. $3 A$ ). The genome-wide significance for this linkage is $P_{\mathrm{G}}=0.0006$. With control for D8Mit312, composite interval mapping reveals a secondary QTL near D1Mit150 at $100 \mathrm{cM}$ on $\mathrm{Chr}$ $1\left(\mathrm{LRS}=15 ; P_{\mathrm{G}}=0.06\right)$. At this locus, $18 \%$ of the variance in cerebellar weight is independently explained, and each $B$ allele is associated with a decrease of $1.3 \mathrm{mg}$ (Fig. $3 C$ ). Collectively, these QTLs control $60 \%$ of the variance in adjusted cerebellar weight among BXD strains. A $6.4 \mathrm{mg}$ difference in weight characterizes BXD strains with $B B(n=9)$ or $D D(n=9)$ alleles at both loci (Fig. 4A-C).

\section{QTLs affecting cerebellar volume in BXD mice}

Single marker analysis shows that variation in adjusted cerebellar volume is also associated with the pattern of $B$ and $D$ alleles on distal Chr 8 and Chr 1 (Table 3). Simple interval mapping of Chr 8 again shows the strongest linkage $(\mathrm{LRS}=19.7)$ to be distal to D8Mit312. At this locus, interval mapping estimates $45 \%$ of the variance in cerebellar volume is explained, and each $B$ allele is associated with a decrease of $2.7 \mathrm{~mm}^{3}$ (Figs. 3B, 4D). The genome-wide significance for this linkage is $P_{\mathrm{G}}=0.01$. Interval mapping of Chr 1 shows the strongest linkage between D1Mit113 and D1Mit150 (LRS $\left.=15.6 ; P_{\mathrm{G}}=0.05\right)$. At this locus, $38 \%$ of the variance in cerebellar volume is explained, and each $B$ allele decreases the volume by $2.1 \mathrm{~mm}^{3}$. With control for D8Mit312, composite interval mapping shows a significant independent effect for the Chr 1 locus (LRS $=19.4 ; P_{\mathrm{G}}=0.013 ; R^{2}=27 \% ; B=$ $-1.8 \mathrm{~mm}^{3}$ ) (Fig. 3D). Collectively, these QTLs control $64 \%$ of the variance in adjusted cerebellar volume among BXD strains. A $6.0 \mathrm{~mm}^{3}$ difference in volume characterizes BXD strains with $B B$ $(n=8)$ or $D D(n=9)$ alleles at both loci (similar to Fig. $4 C)$.

The position, as well as the direction and magnitude of effect size, of the loci on Chr 8 and Chr 1 are comparable in both cerebellar weight and volumetric data. Thus, separate data on cerebellar volume and weight collected from independent samples of BXD mice reinforce the discovery of two QTLs that affect cerebellum size in BXD mice. We have named these QTLs Cerebellar size $8 a$ (Cbs8a: Chr 8) and Cerebellar size 1a (Cbs1a: Chr 1). 

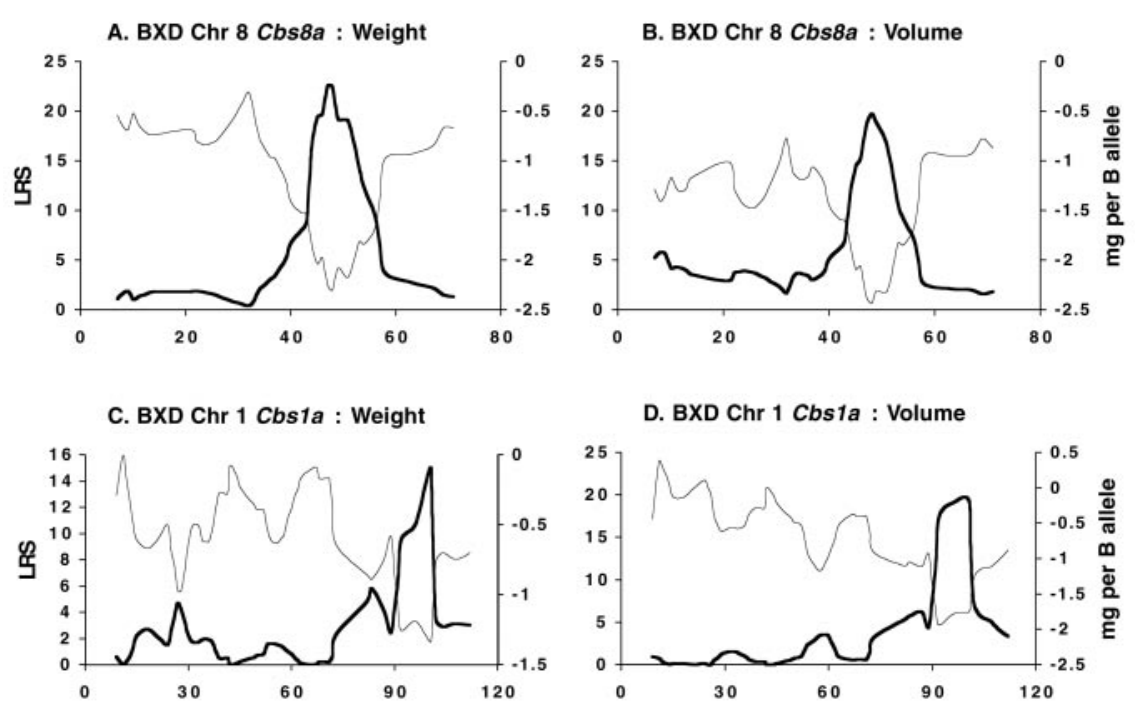

Figure 3. Interval mapping results for $\mathrm{BXD}$ and $\mathrm{F} 2$ mice. In each panel, the thicker black line indicates the likelihood ratio statistic at each chromosomal location (left $y$-axis). The thin black line indicates the associated additive effect at each location (right $y$-axis). The $x$-axis for each panel is in centimorgans. $A$, Interval mapping of Chr 8 for adjusted cerebellar weight in BXD strains. $B$, Interval mapping of Chr 8 for adjusted cerebellar volume in BXD strains. $C$, Composite interval mapping of Chr 1 for adjusted cerebellar weight in BXD strains. $D$, Composite interval mapping of Chr 1 for adjusted cerebellar volume in BXD strains. E, Interval mapping of $\mathrm{Chr} 1$ for adjusted cerebellar weight in F2 mice. $F$, Interval mapping of Chr 14 for adjusted cerebellar weight in F2 mice. $G$, Interval mapping of Chr 19 for adjusted cerebellar weight in $\mathrm{F} 2$ mice. $H$, Interval mapping of $\mathrm{Chr} 19$ for adjusted cerebellar weight in BXD mice.
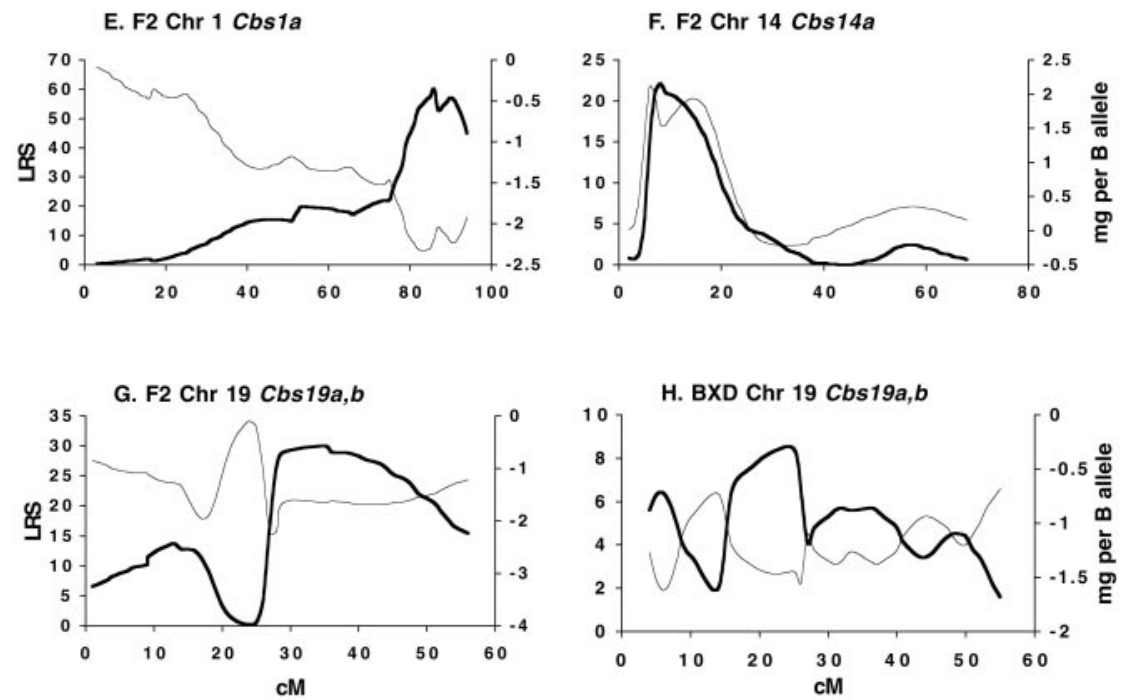

\section{QTLs affecting IGL volume in BXD mice}

The volume of the cell-dense internal granule layer is most strongly linked to Cbs8a and Cbsla (Table 4, Fig. 4E). Simple interval mapping of Chr 8 shows the strongest linkage (LRS = $14.2 ; P_{\mathrm{G}}=0.08$ ) to be distal to D8Mit312 at $45 \mathrm{cM}$. At this locus, $35 \%$ of the variance in IGL volume is explained, and each $B$ allele is associated with a decrease of $1.3 \mathrm{~mm}^{3}$. For the volume of the rest of the cerebellum, the strongest linkage is to Chr 4 (D4Mit303 at $48.5 \mathrm{cM}$ ) (Table 5). Interestingly, $B$ alleles at D4Mit303 add volume to the white matter. However, this putative locus attains only suggestive genome-wide significance $\left(\mathrm{LRS}=13.0 ; P_{\mathrm{G}}=\right.$ 0.13). The next strongest linkages are the familiar Cbs $8 a$ and Cbs1a loci, but neither these loci nor any others attain genomewide significance $\left(P_{\mathrm{G}}=0.53\right.$ at $\left.C b s 8 a\right)$.

\section{Cbs8a is linked to fissure number}

Neumann et al. (1993) previously reported that three loci on chromosomes 5, 7, and 11 affect cerebellar fissure number in 26 BXD strains. We remapped these data with the larger set of genetic markers used in our study. We verified the linkages to chromosomes 5, 7, and 11, and we also discovered that $C b s 8 a$ is putatively linked to the number of fissures $(\mathrm{LRS}=8.3 ; p=$
0.0054). BXD strains with $D$ alleles at $D 8 M i t 312$ have on average one more fissure than strains with $B$ alleles (Fig. $4 F$ ).

\section{QTLs affecting cerebellar weight in F2 mice}

Single marker analysis of the F2 mice reveals highly significant linkage to Chr 1 and $\mathrm{Chr} 19$ and significant linkage to $\mathrm{Chr} 14$ (Table 6). These linkages are first evaluated with simple interval mapping, then with composite interval mapping, and then in combination.

Simple interval mapping of Chr 1 results in an LRS of 60.0 near D1Mit57 at $100 \mathrm{cM}$. The genome-wide significance of this LRS is $P_{\mathrm{G}}<0.0001$. At the peak LRS (Fig. $3 E$ ), interval mapping estimates $30 \%$ of the variance in adjusted cerebellum weight is explained, and each $B$ allele decreases cerebellar weight by 2.2 mg. $D$ alleles are dominant at this locus, and the dominance deviation amounts to $1.0 \mathrm{mg}$. The 2-LOD support interval for this locus, 81-92 cM, overlaps that observed for the Chr 1 locus in the BXD strains of $89-102 \mathrm{cM}$. This strong linkage is therefore compelling support for Cbsla.

Simple interval mapping of Chr 19 reveals an LRS of 30 near D19Mit38 at $35 \mathrm{cM}$. The genome-wide significance of this LRS is $P_{\mathrm{G}}<0.001$. At the peak LRS (Fig. $3 G$ ), this locus explains $15 \%$ 


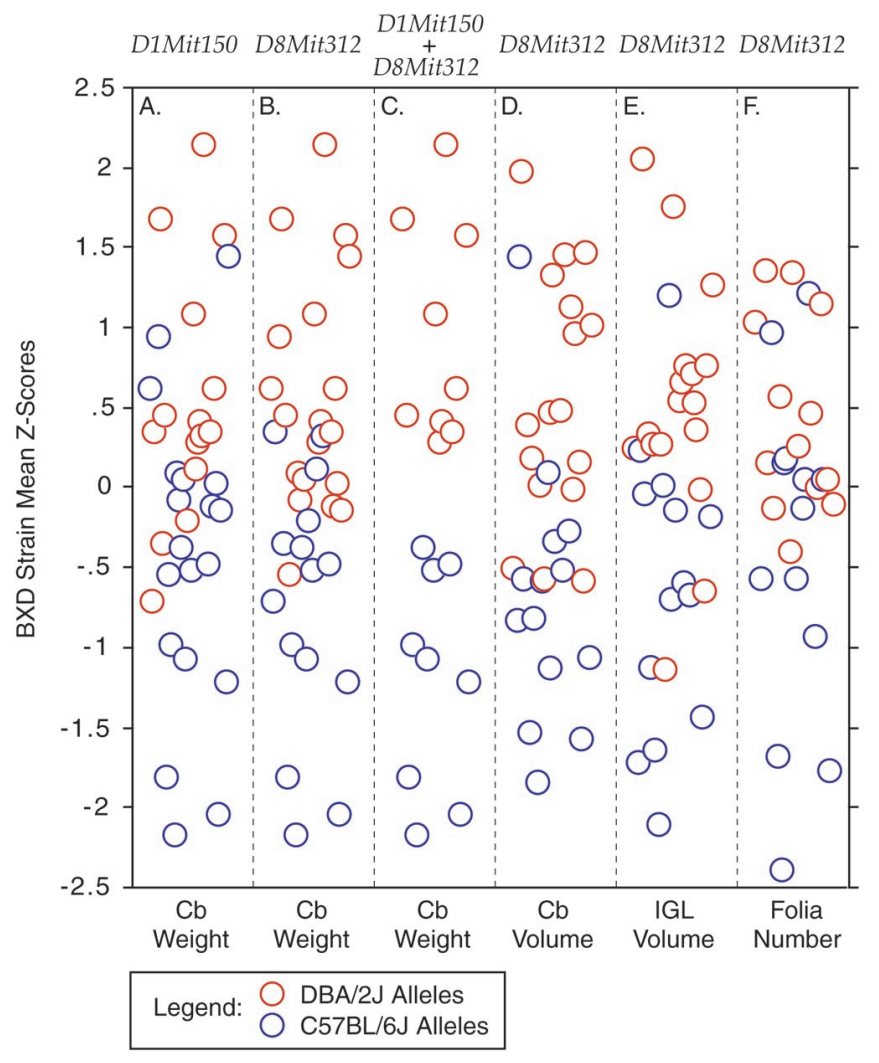

Figure 4. Dot plots for BXD cerebellar strain means at microsatellite markers D1Mit150 and D8Mit312, split by genotype. The $y$-axis has been standardized to present different phenotypes on the same scale and dots have been jittered horizontally for visibility. Adjusted cerebellar weight at D1Mit150 $(A)$ and D8Mit312 (B). C, Combined effect from having $D$ or $B$ alleles at both D1Mit150 and D8Mit312. D, Adjusted cerebellar volume at D8Mit312. Results for volume are similar to $A$ and $C$ for weight and are not shown. E, Adjusted IGL volume at D8Mit312. F Folia number at D8Mit312.

Table 3. Significant comparisonwise linkages for adjusted cerebellar volume in BXD mice

\begin{tabular}{lcrlll} 
Locus & Chr:cM & LRS & $\begin{array}{l}\text { Percent } \\
\text { variance } \\
\text { explained }\end{array}$ & Probability & $\begin{array}{l}\text { Additive } \\
\text { effect per } \\
\text { B allele }\end{array}$ \\
\hline D1Mit113 & $1: 92$ & 15.6 & 38 & $7.7 \mathrm{e}-5$ & -2.08 \\
D1Mit150 & $1: 100$ & 13.4 & 33 & 0.0003 & -1.95 \\
D1Mit426 & $1: 101$ & 14.4 & 35 & 0.0002 & -2.00 \\
D4Mit303 & $4: 49$ & 8.1 & 21 & 0.004 & +1.61 \\
D8Mit147 & $8: 43$ & 11.4 & 28 & 0.0007 & -1.83 \\
D8Mit312 & $8: 45$ & 15.3 & 37 & $9.3 \mathrm{e}-5$ & -2.06 \\
D8Mit211 & $8: 49$ & 18.8 & 44 & $1.5 \mathrm{e}-5$ & -2.31 \\
D8Mit113 & $8: 53$ & 10.7 & 27 & 0.001 & -1.83 \\
D16Mit106 & $16: 69$ & 7.4 & 19 & 0.007 & +1.57 \\
\hline
\end{tabular}

The criteria for significance was set to $\alpha=0.01$.

of the variance in adjusted cerebellar weight. Each $B$ allele decreases cerebellar weight by $1.65 \mathrm{mg}$, and $D$ alleles are dominant $(0.5 \mathrm{mg})$. In BXD strains there is additional support for linkage of adjusted cerebellar weight to Chr 19 (Table 2). Close to $35 \mathrm{cM}$, this linkage is significant with a comparisonwise $\alpha$ of 0.05 (D19Mit13 at $33 \mathrm{cM} ; p=0.02$ ). We have named this locus Cbs19a. There is also a suggestive linkage at the more proximal
Table 4. Significant comparisonwise linkages for adjusted internal granule volume in BXD mice

\begin{tabular}{lcrlll} 
Locus & Chr:cM & LRS & $\begin{array}{l}\text { Percent } \\
\text { variance } \\
\text { explained }\end{array}$ & Probability & $\begin{array}{l}\text { Additive } \\
\text { effect per } \\
\text { B allele }\end{array}$ \\
\hline D1Mit113 & $1: 92$ & 8.9 & 22 & 0.003 & -0.99 \\
D1Mit150 & $1: 100$ & 7.3 & 18 & 0.007 & -0.91 \\
D1Mit426 & $1: 101$ & 10.1 & 25 & 0.001 & -1.05 \\
D5Mit372 & $5: 73$ & 7.0 & 18 & 0.008 & -0.89 \\
D5Mit168 & $5: 80$ & 8.5 & 21 & 0.004 & -0.98 \\
D6Mit236 & $6: 3$ & 7.9 & 20 & 0.005 & -0.95 \\
D6Mit33 & $6: 26$ & 7.7 & 19 & 0.006 & -0.97 \\
D6Mit183 & $6: 27$ & 8.6 & 22 & 0.003 & -1.04 \\
D6Mit29 & $6: 37$ & 8.4 & 21 & 0.004 & -0.97 \\
D7Mit114 & $7: 8$ & 8.4 & 21 & 0.004 & +1.10 \\
D7Mit227 & $7: 17$ & 7.2 & 18 & 0.007 & +0.91 \\
D8Mit145 & $8: 33$ & 8.0 & 20 & 0.005 & -0.95 \\
D8Mit147 & $8: 43$ & 10.5 & 26 & 0.001 & -1.07 \\
D8Mit312 & $8: 45$ & 12.8 & 32 & 0.0003 & -1.16 \\
D8Mit211 & $8: 49$ & 12.7 & 31 & 0.0004 & -1.20 \\
D8Mit113 & $8: 53$ & 8.5 & 21 & 0.003 & -1.00 \\
D16Mit152 & $16: 57$ & 8.8 & 22 & 0.003 & +1.01 \\
\hline
\end{tabular}

The criteria for significance was set to $\alpha=0.01$.

Table 5. Significant comparisonwise linkages for adjusted cerebellar "white matter" (total volume - IGL volume) in BXD mice

\begin{tabular}{lcrlll} 
Locus & Chr:cM & LRS & $\begin{array}{l}\text { Percent } \\
\text { variance } \\
\text { explained }\end{array}$ & Probability & $\begin{array}{l}\text { Additive } \\
\text { effect per } \\
\text { B allele }\end{array}$ \\
\hline D1Mit113 & $1: 92$ & 9.8 & 25 & 0.002 & -0.98 \\
D1Mit150 & $1: 100$ & 9.1 & 23 & 0.002 & -0.95 \\
D1Mit426 & $1: 101$ & 7.6 & 19 & 0.006 & -0.87 \\
D4Mit303 & $4: 49$ & 13.0 & 33 & 0.0003 & +1.13 \\
D8Mit211 & $8: 49$ & 9.1 & 23 & 0.003 & -0.99 \\
D10Mit10 & $10: 51$ & 7.5 & 19 & 0.006 & -0.90 \\
D16Mit106 & $16: 69$ & 6.7 & 17 & 0.01 & +0.86
\end{tabular}

The criteria for significance was set to $\alpha=0.01$.

end of Chr 19 in both BXD and F2 mice. The comparisonwise probability at the marker D19Mit109 $(4 \mathrm{cM})$ in BXD mice is $p=$ 0.017 , and in F2 mice it is $p=0.035$. The combined probability, using Fisher's method (Sokal and Rohlf, 1995), is $p=0.005$. The additive effect as this locus is approximately $-1 \mathrm{mg}$ per $B$ allele. We have provisionally named this locus $C b s 19 b$.

Finally, simple interval mapping of Chr 14 demonstrates linkage with an LRS of 22 near D14Mit207 at $7.7 \mathrm{cM}$. Interval mapping estimates that Cbs $14 a$ explains $11 \%$ of the variation in cerebellar weight. $B$ alleles increase cerebellar weight by $1.5 \mathrm{mg}$ per allele and show a dominance deviation of $0.6 \mathrm{mg}$ (Fig. $3 E$ ). No evidence for linkage near this locus is found across BXD strains. We provisionally refer to this locus as Cbs14a.

With composite interval mapping, it is possible to assess the incremental or independent influence for one of several QTLs affecting a trait. Controlling unlinked QTLs may also increase the power to detect secondary QTLs. By controlling the QTL linked to D1Mit57, the LRS for the Cbs19a locus increases from 30 to 39.1, and the LRS for Cbs14a increases from 22 to 25. Effect size estimates and positions remain essentially unaltered. No additional loci reach genome-wide significance, 


\begin{tabular}{|c|c|c|c|c|c|c|}
\hline \multicolumn{7}{|c|}{$\begin{array}{l}\text { Table 6. Significant comparisonwise linkages for adjusted cerebellar } \\
\text { weight in F2 mice }\end{array}$} \\
\hline Locus & Chr:cM & LRS & $\begin{array}{l}\text { Percent } \\
\text { variance } \\
\text { explained }\end{array}$ & Probability & $\begin{array}{l}\text { Additive } \\
\text { effect per } \\
\text { B allele }\end{array}$ & $\begin{array}{l}\text { Dominance } \\
\text { deviation }\end{array}$ \\
\hline D1Mit80 & $1: 51$ & 16.2 & 8 & 0.0003 & -1.10 & -0.88 \\
\hline D1Mit387 & $1: 65$ & 17.8 & 9 & 0.0001 & -1.26 & +0.10 \\
\hline D1Mit103 & $1: 75$ & 24.2 & 12 & $5.7 \mathrm{e}-6$ & -1.49 & -0.76 \\
\hline D1Mit57 & $1: 85$ & 66.0 & 32 & $4.6 e-15$ & -2.26 & -1.09 \\
\hline D1Mit145 & $1: 87$ & 51.9 & 25 & $5.3 \mathrm{e}-12$ & -2.01 & -0.77 \\
\hline D1Mit356 & 1:94 & 42.9 & 21 & $4.9 \mathrm{e}-10$ & -1.82 & -0.31 \\
\hline D11Mit78 & $11: 4$ & 10.1 & 5 & 0.006 & -0.13 & -1.41 \\
\hline D11Mit82 & $11: 11$ & 12.2 & 6 & 0.002 & -0.01 & -1.54 \\
\hline D12Mit2 & $12: 16$ & 12.1 & 6 & 0.002 & +1.09 & +0.23 \\
\hline D12Mit114 & $12: 23$ & 11.9 & 5 & 0.003 & +0.95 & +0.72 \\
\hline D14Mit207 & $14: 8$ & 22.2 & 11 & $1.5 \mathrm{e}-5$ & +1.47 & +0.61 \\
\hline D19Mit127 & $19: 9$ & 11.5 & 5 & 0.003 & -1.10 & +0.47 \\
\hline D19Mit16 & $19: 13$ & 13.6 & 6 & 0.001 & -1.24 & +0.33 \\
\hline D19Mit89 & $19: 28$ & 29.2 & 14 & $4.5 \mathrm{e}-7$ & -1.64 & +0.58 \\
\hline D19Mit38 & $19: 35$ & 29.2 & 14 & $4.5 \mathrm{e}-7$ & -1.59 & +0.12 \\
\hline D19Mit137 & $19: 56$ & 14.1 & 7 & 0.0009 & -1.15 & +0.17 \\
\hline
\end{tabular}

The criteria for significance was set to $\alpha=0.01$.

Table 7. Epistasis ANOVA for QTLs controlling cerebellar weight in BXD mice ${ }^{a}$

\begin{tabular}{lrrrrr} 
Source & df & \multicolumn{1}{c}{ SS } & \multicolumn{1}{c}{ MS } & F ratio & Probability \\
\hline Const & 1 & 92717.7 & 92717.7 & 26352 & $\leq 0.0001$ \\
Cbs1a & 1 & 62.2 & 62.2 & 17.6 & 0.0002 \\
Cbs8a & 1 & 111.2 & 111.2 & 31.6 & $\leq 0.0001$ \\
Cbs1a*Cbs8a & 1 & 2.6 & 2.6 & 0.7 & 0.3957 \\
Error & 30 & 105.5 & 3.5 & & \\
Total & 33 & 299.6 & & & \\
\hline
\end{tabular}

${ }^{a}$ Results for cerebellar volume are not different.

although D12Mit2 is suggestive (LRS =15.4). When both the Cbs1a and Cbs19a are controlled, the LRS for the Chr 14 locus is no longer significant (LRS $=0.9$ ), indicating a lack of strong independent effect between $C b s 19 a$ and $C b s 14 a$. No additional loci reach genome-wide significance, although D7Mit238 is suggestive $(\mathrm{LRS}=15.5)$. Neither of these additional suggestive loci are supported in the BXD data.

Considered together, these QTLs have appreciable effect size in the F2 mice. For example, a $7 \mathrm{mg}$ difference is found between mice $(n=12)$ homozygous for $B$ and $D$ alleles at $C b s 1 a$ and Cbs $14 a$, respectively, and mice $(n=11)$ homozygous for $D$ and $B$ alleles at these same loci, respectively. An $8 \mathrm{mg}$ difference is found in mice $(n=12)$ homozygous for $B$ alleles at Cbsla and Cbs19a and mice $(n=6)$ homozygous for $D$ alleles at these loci. All four loci together account for $46 \%$ of the variance in adjusted cerebellar weight in the F2 mice.

\section{Epistasis}

The effect of one QTL may depend on allelic differences at another QTL. To examine epistasis between the QTLs identified in the present study, we tested two-way ANOVA interactions between loci (Table 7). No two-way interactions were found to be significant, and therefore the QTLs we report here do not appear to interact epistatically.

\section{DISCUSSION}

\section{Synopsis}

We have discovered five new QTLs that are the among first normal gene variants known to modulate the size of the vertebrate cerebellum. We have named these QTLs Cbs1a, Cbs $8 a$, $C b s 14 a, C b s 19 a$, and Cbs19b. Among BXD recombinant inbred strains, the cerebellum averages $52 \mathrm{mg}$ (12.4\% of the brain) and ranges $18 \mathrm{mg}$ in size. The two quantitative trait loci on Chr 1 (2-LOD support interval 89-102 cM) and Chr 8 (44-53 cM), are responsible for $\sim 6 \mathrm{mg}$ of this range, a $33 \%$ effect size. In C57BL/ $6 \mathrm{~J} \times \mathrm{DBA} / 2 \mathrm{~J}$ F2 mice, the cerebellum averages $62 \mathrm{mg}(12.9 \%$ of the brain) and ranges in size $\sim 20 \mathrm{mg}$. Four QTLs on Chrs 1 (81-92 cM), 14 (5-16 cM), and 19 (28-56 cM, 4-21 cM) are responsible for $\sim 7 \mathrm{mg}$ of this range, a $35 \%$ effect size. In mapping these QTLs, the effects of brain size, sex, age, and body weight on cerebellar size were examined before mapping and statistically controlled when necessary. Apart from brain size, which accounted for $\sim 50 \%$ of cerebellar weight, we detected no discernable, independent effects on total cerebellar size for sex, age, or body weight.

\section{Regional cerebellar effects of Cbs8a}

Regional effects of cerebellar size QTLs were explored in BXD strains by examining the volume of the cell-rich internal granule layer versus the remaining volume. Our measurement of the IGL contained the somas of two of the main cell types in the cerebellum, the Purkinje, and the granule neurons. The remaining cerebellar volume included the molecular layer where granule and Purkinje cells synapse, the internal white matter, and the deep cerebellar nuclei. Although the IGL and remaining cerebellum are genetically correlated, we found that age and body weight correlated differently with these parts of the cerebellum, and we found a difference in the strength of linkage to the Chr 8 locus Cbs8a. Age and body weight correlated more strongly with the aggregate volume of the molecular layer, internal white matter, and deep nuclei than with the volume of the internal granule layer. BXD strain differences in internal granule layer volume are more strongly associated with genotypes at $\operatorname{Cbs} 8 a\left(P_{\mathrm{G}}=0.08\right)$ than the volume of the remaining cerebellum $\left(P_{\mathrm{G}}=0.53\right)$. This suggests that the main effect of $C b s 8 a$ is on cell population size. This is consistent with evidence for linkage between $C b s 8 a$ and the number of fissures, in which $D$ alleles that are associated with increased IGL volume are also associated with greater numbers of fissures. Although mechanisms of fissure formation are not well understood, a role for the proliferation of granule cells in fissure formation has been suggested (Mares and Lodin, 1970), and it has been noted that overall size of the cerebellum accounts significantly for fissure number (Wahlsten and Andison, 1991). Over expression of Zipro1 results in increased granule cell proliferation and increased numbers of intralobular fissures (Yang et al., 1999). Although Cbs8a is not Zipro1 (which resides on Chr 5), it is tempting to postulate that it may be a downstream target of Zipro1 or part of a network in which Zipro1 is involved.

\section{Specificity of QTL effects}

A difficult problem in correlational analyses is specificity of causation. For instance, if we mapped cerebellum size without considering the effects of total brain size, we could map genes that do not specifically affect the cerebellum. In the present study we used residuals from linear regression models that included brain size 
covariates. This improves our ability to map genes with selective effects on the cerebellum. Another approach to the problem of specificity is to gather many phenotypes from the same mice. For instance, in two companion studies we report QTLs in BXD and BDF2 mice for olfactory bulb (Williams et al., 2001) and hippocampus (Lu et al., 2001). QTLs for olfactory bulb weight were discovered on chromosomes 4, 6, 11, and 17. QTLs for hippocampus weight were discovered on chromosomes 1 and 5. Bulb4a on Chr 4 and Hippla on Chr 1 map within the same 2-LOD support intervals as the putative linkage of cerebellar white matter volume to Chr 4 and the linkage of Cbsla to Chr 1, respectively. The linkage of Cbs1a distal Chr 1 reported here is independent of that reported for hippocampus at Hippla by Lu et al. (2001); a linear model predicting F2 weight of the cerebellum from D1Mit57 remains significant with hippocampus weight used as a covariate (data not shown). Yet another approach to the problem of specificity is to gather more refined phenotypes related to the primary phenotype, as Lu et al. (2001) did for hippocampal volume, and as we have done for cerebellar volume. Lu et al. (2001) reported that Hippla exhibits shared effects on the volume of the hippocampal complex, the hippocampus proper, the pyramidal cell layer, and the granule cell layer. Hippla was also observed to overlap a previously mapped locus affecting the volume of the mossy fiber projection to CA3 from granule cells (Lassalle et al., 1999). In a similar way, by remapping cerebellar folial pattern in BXD strains (Neumann et al., 1993) with a more complete marker set, not only did we see the linkages previously reported by Neumann et al. (1993) on Chrs 5, 7, and 11, but we also discovered that $C b s 8 a$ is linked to the number of fissures (LRS = 8.3; $p=0.005$ ), with $D$ alleles adding fissures. Thus, DBA/2J alleles at $C b s 8 a$ increase cerebellar weight, cerebellar volume, internal granule layer volume, and the number of cerebellar folia in BXD mice. These observations illustrate one of the advantages of recombinant inbred strains: data are cumulative over time and across laboratories. However, they also illustrate the problem of specificity of QTL action and highlight a need for improved mapping resources and methods. QTL fine mapping (Darvasi, 1998), perhaps in combination with multiple trait QTL mapping methods (Jiang and Zeng, 1995), may help significantly in this regard.

\section{RI strains, F2 intercrosses, and advanced intercrosses}

In the present study we used recombinant inbred strains derived from the parental strains C57BL/6J and DBA/2J as well as the F2 intercross progeny. Because both RI and F2 mice used in this study were derived from the same parental strains, the same alleles are assumed to be segregating in each mapping panel. However, we detected significant differences between the 34 BXD strains and our F2 progeny. The F2 progeny had heavier bodies, brains, and cerebella. Such effects probably reflect heterosis (hybrid vigor). Possibly related to these phenotypic differences, two of the five QTLs we discovered, those on Chr 8 and Chr 14, were not detected in both RI and F2 mapping panels. However, $C b s 8 a$ finds support in two separate samples of BXD mice measured for both cerebellar weight and volume. Loci that are not replicated may also reflect the random assortment of alleles in relatively small samples or a mutation that has occurred in either the $\mathrm{C} 57 \mathrm{BL} / 6 \mathrm{~J}$ or DBA/2J genomes since creation of the BXD strains in the 1970s and 1980s. We are currently investigating a third mapping panel derived from C57BL/6J and DBA/2J strains. This is an advanced intercross, created by outbreeding F2 mice. Examining cerebellar size and IGL volume in this panel will allow an additional opportunity to test the QTLs we have reported here and should reduce significantly the 2-LOD support intervals of confirmed QTLs (Darvasi, 1998). Fine mapping of Cbs $8 a$ can alternatively proceed using a recombinant inbred segregation test (Darvasi, 1998).

\section{Candidate genes}

The goal of our QTL mapping is to identify genes influencing cerebellar development. Once linkage is established, further study can proceed in three directions that complement the main goal of complex trait analysis (Moisan, 1999; Williams, 2000). First, mapping can continue with panels designed to reduce the interval containing the QTL, such as with advanced intercross or congenic lines (high-resolution mapping). Second, the effects of variants in identified genes near the QTL can be assessed (candidate gene analysis). Third, the phenotype associated with a QTL can be more rigorously defined or examined during development. For example, in a developmental analysis Strom and Williams (1998) established that a QTL that modulates retinal ganglion cell number acts through proliferation rather than cell death, thereby effectively eliminating the need to examine candidate genes that engage apoptotic mechanisms. The 2-LOD support intervals of the QTLs we report here are not yet sufficiently precise for effective candidate gene analysis, but we highlight several genes with identified effects on the cerebellum lie within these intervals.

On chromosome 1 , the dreher mutation $(d r ; 88.2 \mathrm{cM})$ is known to have drastic effects on the cerebellum (Sekiguchi et al., 1992). Recent work reveals $d r$ to be a mutation of the LIM homeodoman protein Lmxla, which disrupts development of the roof plate, resulting in part in the loss of granule neurons in the cerebellum (Millonig et al., 2000). Also on Chr 1 is the retinoid $\times$ receptor gene (Rxrg; $88.1 \mathrm{cM})$. Retinoic acid receptors are expressed in the cerebellum of the rat, and granule cell loss results from teratogenic effects of the ligand (Yamamoto et al., 1999).

On chromosome 8 , four of the cadherin $(C d h)$ genes reside within the 2-LOD support interval for $C b s 8 a(C d h 5,51 \mathrm{cM} ; C d h 8$, $46.5 \mathrm{cM}$; Cdh11, $46.5 \mathrm{cM}$; Cdh16, $50.0 \mathrm{cM})$. Cadherins are cell adhesion molecules with widespread morphogenetic effects and are thought to be important in regionalization of the CNS. Cadherin 8 is expressed widely in the developing mouse brain and shows a patterned distribution in the cerebellum (Korematsu and Redies, 1997; Korematsu et al., 1998). Also on chromosome 8, Cerebellin1 (Kavety et al., 1994), is highly enriched in the cerebellum (Urade et al., 1991; Pang et al., 2000), and its levels are decreased in mice that exhibit a loss of cerebellar granule neurons (Slemmon et al., 1988).

On chromosome 14, both the gene for bone morphogenetic protein $4(B m p 4 ; 14 \mathrm{cM})$ and for bone morphogenetic protein receptor 1A (Bmprla; $13 \mathrm{cM}$ ) reside within the 2-LOD interval for Cbs14a. Work by Alder et al. (1999) suggests that bone morphogenetic proteins can initiate granule cell genesis, and work by Iantosca et al. (1999) suggests that Bmp4 may regulate granule cell number through inhibition of apoptosis.

Finally, on chromosome 19, both genes for fibroblast growth factor $8(F g f 8 ; 45 \mathrm{cM})$ and $\operatorname{Pax} 2(43 \mathrm{cM})$ reside within the 2-LOD interval for Cbs19a. Both genes are critical to the early development of the cerebellum (Goldowitz and Hamre, 1998). Favor et al. (1996) and Urbanek et al. (1997) showed that inactivation of Pax 2 can lead to loss of the cerebellum and posterior midbrain. Liu et al. (1999) have more recently 
showed that $F g f 8$ regulates the cascade of genes that transform the hindbrain into cerebellar structures.

The confidence intervals for the QTLs we have discovered are homologous to the following chromosomal regions in humans: Cbs1a: 1q23-43, Cbs8a: 16q12-16q22, Cbs14a: 10q11-23, Cbs19a: 9q13-q24 and 11q12-q13, Cbs19b: 10q23-qter. The conserved sequence similarity among mammals makes the likelihood high that identification of genes that influence cerebellar development in mice will aid discovery of homologous genes in humans.

\section{REFERENCES}

Alder J, Lee KJ, Jessell TM, Hatten ME (1999) Generation of cerebellar granule neurons in vivo by transplantation of BMP-treated neural progenitor cells. Nat Neurosci 2:535-540.

Barton RA, Harvey PH (2000) Mosaic evolution of brain structure in mammals. Nature 405:1055-1058.

Butler W, Hodos AB (1996) Comparative vertebrate neuroanatomy: evolution and adaptation. New York: Wiley.

Churchill GA, Doerge RW (1994) Empirical threshold values for quantitative trait mapping. Genetics 138:963-971.

Cooper PA, Benno RH, Hahn ME, Hewitt JK (1991) Genetic analysis of cerebellar foliation patterns in mice (Mus musculus). Behav Genet 21:405-419.

Darvasi A (1998) Experimental strategies for the genetic dissection of complex traits in animals. Nat Genet 18:19-24.

Dietrich WF, Katz H, Lincoln SE (1992) A genetic map of the mouse suitable for typing in intraspecific crosses. Genetics 131:423-447.

Dietrich WF, Miller JC, Steen RG, Merchant M, Damron D, Nahf R, Gross A, Joyce DC, Wessel M, Dredge RD, Marquis A, Stein LD, Goodman N, Page DC, Lander ES (1994) A genetic map of the mouse with 4,006 simple sequence length polymorphisms. Nat Genet 7:220-245.

Don RH, Cox PT, Wainwright BJ, Baker K, Mattick JS (1991) "Touchdown" PCR to circumvent spurious priming during gene amplification. Nucleic Acids Res 19:4008.

Favor J, Sandulache R, Neuhauser-Klaus A, Pretsch W, Chatterjee B, Senft E, Wurst W, Blanquet V, Grimes P, Sporle R, Schughart K (1996) The mouse Pax2(1Neu) mutation is identical to a human PAX2 mutation in a family with renal-coloboma syndrome and results in developmental defects of the brain, ear, eye, and kidney. Proc Natl Acad Sci USA 93:13870-13875.

Finlay BL, Darlington RB (1995) Linked regularities in the development and evolution of mammalian brains. Science 268:1578-1584.

Goldowitz D, Eisenman LM (1992) Genetic mutations affecting murine cerebellar structure and function. In: Genetically defined animal models of neurobehavioral dysfunction (Driscoll P, ed), pp 66-88. Boston: Birkhauser.

Goldowitz D, Hamre K (1998) The cells and molecules that make a cerebellum. Trends Neurosci 21:375-382.

Haley CS, Knott SA (1992) A simple regression method for mapping quantitative trait loci in line crosses using flanking markers. Heredity 69:315-324.

Hegmann JP, Possidente B (1981) Estimating genetic correlations from inbred strains. Behav Genet 11:103-114.

Heintz N, Zoghbi HY (2000) Insights from mouse models into the molecular basis of neurodegeneration. Annu Rev Physiol 62:779-802.

Herrup K, Kuemerle B (1997) The compartmentalization of the cerebellum. Annu Rev Neurosci 20:61-90.

Iantosca MR, McPherson CE, Ho SY, Maxwell GD (1999) Bone morphogenetic proteins-2 and -4 attenuate apoptosis in a cerebellar primitive neuroectodermal tumor cell line. J Neurosci Res 56:248-258.

Inouye M, Oda S (1980) Strain-specific variations in the folial pattern of the mouse cerebellum. J Comp Neurol 190:357-362.

Jiang C, Zeng ZB (1995) Multiple trait analysis of genetic mapping for quantitative trait loci. Genetics 140:1111-1127.

Joyner AL, Herrup K, Auerbach A, Davis CA, Rossant J (1991) Subtle cerebellar phenotype in mice homozygous for a targeted deletion of the En-2 homeobox. Science 251:1239-1243.

Kavety B, Jenkins NA, Fletcher CF, Copeland NG, Morgan JI (1994) Genomic structure and mapping of precerebellin and a precerebellinrelated gene. Brain Res Mol Brain Res 27:152-156.

Korematsu K, Redies C (1997) Expression of cadherin-8 mRNA in the developing mouse central nervous system. J Comp Neurol 387:291-306.

Korematsu K, Nishi T, Okamura A, Goto S, Morioka M, Hamada J, Ushio Y (1998) Cadherin-8 protein expression in gray matter structures and nerve fibers of the neonatal and adult mouse brain. Neuroscience 87:303-315.

Kuemerle B, Zanjani H, Joyner A, Herrup K (1997) Pattern deformities and cell loss in Engrailed-2 mutant mice suggest two separate patterning events during cerebellar development. J Neurosci 17:7881-7889.

Laird PW, Zijderveld A, Linders K, Rudnicki M, Jaenisch R, Berns A (1991) Simplified mammalian DNA isolation procedure. Nucleic Acids Res 19:4293.

Lander ES, Kruglyak L (1995) Genetic dissection of complex traits: guidelines for interpreting and reporting linkage results. Nat Genet 11:241-247.

Lassalle JM, Halley H, Milhand JM, Roullet P (1999) Genetic architecture of the hippocampus mossy fiber subfields in the BXD R1 mouse strain series: a preliminary QTL analyses. Behav Genet 29:273-282.

LeRoy-Duflos I (2001) Possible causal relationships between cerebellar patterns of foliation and hind limb coordination in laboratory mice: a quantitative trait locus analysis. Behav Genet, in press.

Liu A, Losos K, Joyner AL (1999) FGF8 can activate Gbx2 and transform regions of the rostral mouse brain into a hindbrain fate. Development 126:4827-4838.

Liu BH (1998) Statistical genomics: linkage, mapping, and QTL analysis, pp 100. New York: CRC.

Llinás RR, Walton KD (1998) Cerebellum. In: The synaptic organization of the brain, Ed 4, (Shepherd GM, ed), pp 255-288. New York: Oxford UP.

Love JM, Knight AM, McAleer MA, Todd JA (1990) Towards construction of a high resolution map of the mouse genome using PCRanalyzed microsatellites. Nucleic Acids Res 18:4123-4130.

Lu L, Airey DC, Williams RW (2001) Genetic architecture of the mouse hippocampus: identification of gene loci with specific effects on hippocampal size. J Neurosci 21:3503-3514.

Lynch M, Walsh B (1998) Genetics and analysis of quantitative traits. Sunderland, MA: Sinauer.

Millen K, Wurst W, Herrup K, Joyner A (1994) Abnormal embryonic cerebellar development and patterning of postnatal foliation in two mouse Engrailed-2 mutants. Development 120:695-706.

Millonig JH, Millen KJ, Hatten ME (2000) The mouse Dreher gene Lmxla controls formation of the roof plate in the vertebrate CNS. Nature 403:764-769.

Manly KF, Olson JM (1999) Overview of QTL mapping software and introduction to map manager QT. Mamm Genome 10:327-334.

Mares V, Lodin Z (1970) The cellular kinetics of the developing mouse cerebellum II. The function of the external granule layer in the process of gyrification. Brain Res 23:343-352.

Moisan MP (1999) From QTL detection to gene identification. In: Neurobehavioral genetics: methods and applications (Jones BC, Mormede P, eds), pp 77-91. New York: CRC.

Neumann PE, Mueller GG, Sidman RL (1990) Identification and mapping of a mouse gene influencing cerebellar folial pattern. Brain Res 524:85-89.

Neumann PE, Garretson JD, Skaboardonis GP, Mueller GG (1993) Genetic analysis of cerebellar folial pattern in crosses of C57BL/6J and DBA/2J inbred mice. Brain Res 619:81-88.

Oberdick J, Baader SL, Schilling K (1998) From zebra stripes to postal zones: deciphering patterns of gene expression in the cerebellum. Trends Neurosci 21:383-390.

Pang Z, Zuo J, Morgan JI (2000) Cbln3, a novel member of the precerebellin family that binds specifically to Clbn1. J Neurosci 20:6333-6339.

Rilling JK, Insel TR (1998) Evolution of the cerebellum in primates: differences in relative volume among monkeys, apes, and humans. Brain Behav Evol 52:308-314.

Rosen GD, Harry JD (1990) Brain volume estimation from serial section measurements: a comparison of methodologies. J Neurosci Methods 35:115-124.

Sekiguchi M, Shimai K, Guo H, Nowakowski RS (1992) Cytoarchitectonic abnormalities in hippocampal formation and cerebellum of dreher mutant mouse. Brain Res Dev Brain Res 67:105-112.

Slemmon JR, Goldowitz D, Blacher R, Morgan JI (1988) Evidence for the transneuronal regulation of cerebellin biosynthesis in developing Purkinje cells. J Neurosci 8:4603-4611.

Sokal RR, Rohlf FJ (1995) Biometry: the principles and practice of statistics in biological research, pp 794-797. New York: Freeman.

Strom RC, Williams RW (1998) Cell production and cell death in the generation of variation in neuron number. J Neurosci 18:9948-9953.

Taylor BA (1989) Recombinant inbred strains. In: Genetic variants and strains of the laboratory mouse, Ed 2 (Lyon ML, Searle AG, eds), pp 773-796. Oxford: Oxford UP.

Taylor BA, Wnek C, Kotlus BS, Roemer N, MacTaggart T, Philli (1999) Genotyping new BXD recombinant inbred mouse strains and comparison of BXD and consensus maps. Mamm Genome 10:335-348.

Urade Y, Oberdick J, Molinar-Rode R, Morgan JI (1991) Precerebellin is a cerebellum-specific protein with similarity to the globular domain of complement C1q B chain. Proc Natl Acad Sci USA 88:1069-1073. 
Urbanek P, Fetka I, Meisler MH, Busslinger M (1997) Cooperation of Pax2 and Pax5 in midbrain and cerebellum development. Proc Natl Acad Sci USA 94:5703-5708.

Voogd J, Glickstein M (1998) The anatomy of the cerebellum. Trends Neurosci 21:370-375.

Wahlsten D, Andison M (1991) Patterns of cerebellar foliation in recombinant inbred mice. Brain Res 557:184-189.

Williams RW (2000) Mapping genes that modulate mouse brain development: a quantitative genetic approach. In: Mouse brain development (Goffinet A, Rakic P, eds), pp 21-49. Berlin: Springer.

Williams RW, Stron RC, Goldowitz D (1998) Natural variation in neuron number in mice is linked to a major quantitative trait locus on $\mathrm{Chr}$ 11. J Neurosci 18:138-146.
Williams RW, Airey DC, Kulkarni A, Zhou G, Lu L (2001) Genetic dissection of the olfactory bulbs of mice: QTLs on chromosomes 4, 6, 11, and 17 modulate bulb size Behav Genet 31:61-77.

Yamamoto M, Ullman D, Drager UC, McCaffery P (1999) Postnatal effects of retinoic acid on cerebellar development. Neurotoxicol Teratol 21:141-146.

Yang XW, Wynder C, Doughty ML, Heintz N (1999) BAC-mediated gene-dosage analysis reveals a role for Zipro1 (Ru49/Zfp38) in progenitor cell proliferation in cerebellum and skin. Nature 22:327-335.

Zhou G, Williams RW (1999) Eye1 and Eye2: gene loci that modulate eye size, lens weight, and retinal area in mouse. Invest Ophthalmol Vis Sci 40:817-825. 